\title{
Comparação de megadados das duas revistas da Anpuh ou Introdução à ciência aberta para historiadores
}

Comparison of Big Data from the two Anpuh Journals or Introduction to Open Science for Historians

Oldimar Pontes Cardoso*

Marco Aurélio da Costa ${ }^{\star *}$ Gustavo Ítalo Freire Martins ${ }^{\star * *}$

Waleska Maria Lopes Farias ${ }^{+}$

João Carlos de Melo Silva ${ }^{++}$

\section{RESUMO}

Este artigo analisa o corpus completo da Revista História Hoje (2012-2020) e o corpus da Revista Brasileira de História no mesmo período, utilizando-se do método de cotejamento diacrônico de fontes escritas por redes semântico-temporais e de um algoritmo desenvolvido pelos dois primeiros autores. Suas principais conclusões são a ascensão do uso das palavras "aula" e "consciência" na RHHJ e das palavras "nacional” e "América” na $\mathrm{RBH}$ e a queda do uso das palavras "novo" e "antigo" na RHHJ e das palavras "trabalho", "processo" e "governo" na RBH. Podemos destacar ainda a ascensão repentina das palavras "direi-

\section{ABSTRACT}

This paper analyzes the full corpus of Revista História Hoje (2012-2020) and the corpus of Revista Brasileira de História in the same period using the method of diachronic confrontation of written sources by semantic-temporal networks and an algorithm developed by the first two authors. Its main conclusions are the rise of the use of the words "classroom" and "consciousness" in RHHJ and the words "national" and "America" in $\mathrm{RBH}$ and the fall of the use of the words "new" and "ancient" in $\mathrm{RHHJ}$ and the words "work", "process" and "government" in RBH. We can also highlight the sudden rise of the words

* Netbot Humanidades Digitais Ltda, São Paulo, SP, Brasil. oldimar@gmail.com

** MCBC Informática Ltda, São José dos Campos, SP, Brasil. costa.marco@gmail.com

$* * *$ Universidade Federal do Rio Grande do Norte (UFRN), Natal, RN, Brasil. gustavo.italo. freire@gmail.com

+ Universidade Federal do Rio Grande do Norte (UFRN), Natal, RN, Brasil. waleskamlfarias@ gmail.com

+ + Universidade Federal do Rio Grande do Norte (UFRN), Natal, RN, Brasil. joaocms.prof@ gmail.com 
to" e "humano" na RHHJ e das palavras "antigo" e "antiguidade" na RBH. O artigo funciona como uma introdução à ciência aberta para historiadores porque descreve em detalhes os protocolos de ciência aberta utilizados nesta pesquisa histórica, demonstra como outros pesquisadores poderiam utilizar seus dados, métodos, fluxos de trabalho e protocolos para replicá-la ou realizar pesquisas distintas desta, e ainda indica como tudo isso viabiliza reprodutibilidade científica nas humanidades.

Palavras-chave: Anpuh; ciência aberta; reprodutibilidade científica. "rights" and "human" in RHHJ and the words "ancient" and "antiquity" in $\mathrm{RBH}$. The paper works as an introduction to open science for historians because it describes in detail the open science protocols used in this historical research, it demonstrates how other researchers could use its data, methods, workflows and protocols to replicate it or to conduct other research than this. It also indicates how all of this enables scientific reproducibility in the humanities.

Keywords: Anpuh; open science; scientific reproducibility.

POR QUE PRECISAMOS DE UMA HISTÓRIA ABERTA?

Admitimos que a ciência aberta não tem a mais digna das origens. Segundo a Organisation for Economic Co-operation and Development (OECD), ciência aberta é o ato de tornar "os resultados de pesquisa com financiamento público (publicações e dados de pesquisa) acessíveis ao público em formato digital" (OECD, 2015, p. 7). Esta é uma visão tecnocrática de ciência aberta, pautada apenas na otimização do financiamento público, na ideia de reduzir custos com o acesso a publicações científicas e com a reutilização de dados de pesquisa. É melhor não contar aos tecnocratas que ciência é sempre um investimento público a fundo perdido, que significa obrigatoriamente investir em milhares de pesquisas que não vão nos levar a lugar nenhum em troca de algumas dezenas de pesquisas que nos darão resultados significativos. É impossível prever quais pesquisas darão esses resultados significativos, mas, apesar disso, o investimento generalizado em ciência sempre compensou. Somente economizar com acesso a publicações e reutilização de dados não justifica a existência da ciência aberta. Mas apesar de ela significar muito mais do que a OECD consegue enxergar, é importante ter em mente que a ciência aberta só adquiriu 
prestígio e acesso privilegiado a financiamento por causa desta visão tecnocrática e não das características mais importantes que descrevemos a seguir.

De acordo com Pontika (2015), para além do acesso aberto e dos dados abertos que bastam à OECD, a ciência aberta também implica pesquisa reprodutível aberta (que é, em nossa opinião, a principal característica), definição de ciência aberta (a discussão metacientífica propriamente dita), avaliação de ciência aberta, diretrizes de ciência aberta, políticas de ciência aberta, projetos de ciência aberta e ferramentas de ciência aberta, como vemos na Imagem 1.

Definimos a seguir como a pesquisa que resulta neste artigo tem relação com o que Pontika (2015) chama de "pesquisa reprodutível aberta" e indicamos a leitura do artigo citado e de Koschtial (2021), Christensen (2019) e Bezjak (2018) para a compreensão do restante da taxonomia da ciência aberta descrita na Imagem 1 e sua relação com as humanidades.

No caso específico da pesquisa histórica, a ciência aberta pode contribuir para combater três tradições que ainda existem no campo e contribuem para reduzir a qualidade de suas pesquisas: acesso privilegiado ou exclusivo a fontes, autoridade moral e ensaísmo. Como se trata de atividade ilegal, não é possível definir com precisão o impacto que o acesso privilegiado ou exclusivo a fontes (via uso de poder político ou suborno de funcionários de baixo escalão) tem sobre a pesquisa histórica atual. Mas é fato que a digitalização cada vez maior das fontes disponíveis aos historiadores reduz sensivelmente este problema. E estabelecer o acesso aberto a todas as fontes o eliminará definitivamente. A ausência de fontes abertas também estimula o recurso à autoridade moral, tirando das fontes o foco da argumentação e projetando-o no poder político do historiador que as utilizou. Abrir as fontes inibe o recurso à autoridade moral e devolve o foco da argumentação às fontes, onde ele sempre deveria estar. A distância ou ocultação das fontes também sempre funcionou como um convite ao ensaísmo e a criação de conceitos vagos e generalizantes que mais atrapalham do que ajudam a análise histórica, o que perde o sentido quanto mais as fontes e o diálogo transparente com elas na comunicação da pesquisa adquirem importância nos protocolos da ciência aberta. 
Imagem 1 - Taxonomia da Ciência Aberta.

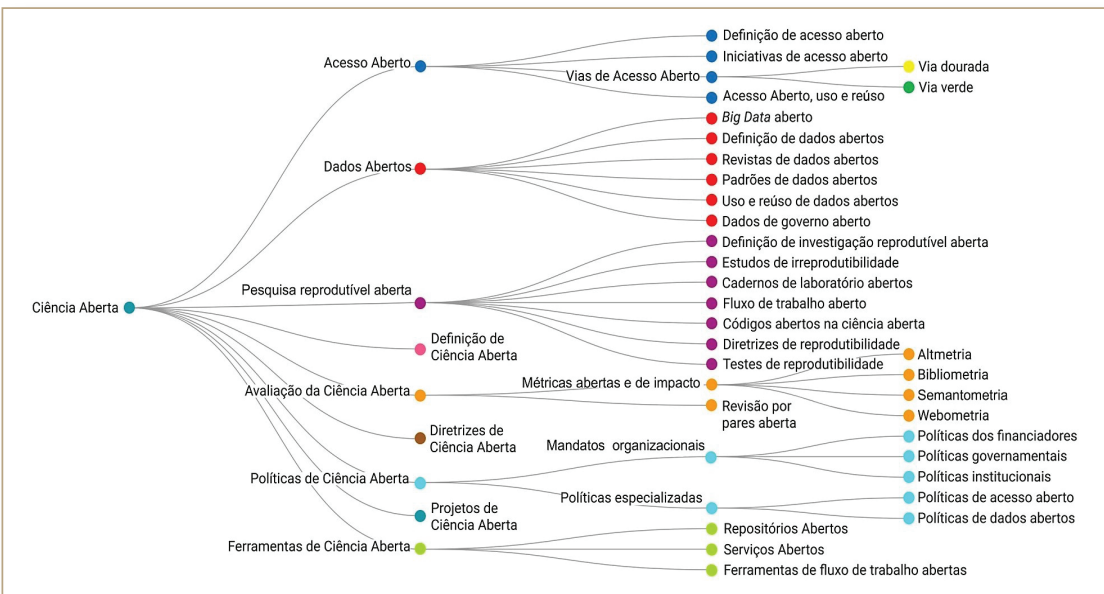

Fonte: Taxonomia da Ciência Aberta. https://figshare.com/articles/figure/TaxonomiadaCinciaAberta/12124002. Acesso em: 02 jul. 2021. Traduzido por Nivaldo Calixto Ribeiro, Lúcia da Silveira, Sarah Rúbia de Oliveira Santos.

Podemos afirmar que esta pesquisa histórica é reprodutível aberta porque obedece aos seguintes protocolos:

1. Todos os seus dados são abertos e disponíveis em um projeto específico hospedado na plataforma Open Science Framework: https://osf.io/ bepqd/;

2. Não apenas os dados originais, mas também os dados tratados, que facilitam futuras pesquisas e viabilizam a reprodutibilidade desta pesquisa, também são abertos;

3. Os seus metadados estão descritos no arquivo _metadata.pdf, na raiz da pasta de dados abertos;

4. Os seus métodos são abertos e descritos no próprio artigo de forma a serem reprodutíveis;

5. Os seus fluxos de trabalho são abertos e descritos no fluxograma da Imagem 2 e no arquivo _workflow.pdf, na raiz da pasta de dados abertos;

6. Todos os seus passos sujeitos a viés no fluxo de trabalho estão explicitados no documento _workflow.pdf;

7. Os seus fluxos de trabalho são automatizados, de forma a viabilizar sua 
futura transposição por qualquer outro pesquisador para um Workflow Management System (DEELMAN, 2017);

8. Todos os códigos utilizados em seus fluxos de trabalho são abertos e se encontram na pasta "code", na raiz da pasta de dados abertos;

9. Todos os dados, códigos e fluxos de trabalho estão vinculados à Licença CC BY Atribuição 4.0 Internacional (CC BY 4.0) - https://creativecommons.org/licenses/by/4.0/deed.pt_BR;

10. Os resultados desta pesquisa encontram-se nesta publicação de acesso aberto.

\section{DADOS, MÉTODOS, FLUXOS DE TRABALHO E PROTOCOLOS}

O que apresentamos aqui é resultado da comparação digital do corpus completo da Revista História Hoje (2012-2020) e do corpus da Revista Brasileira de História no mesmo período sob o método de análise de fontes textuais com base em redes semânticas estabelecido por Silva (2016), que fundamentou o método de cotejamento diacrônico de fontes escritas por redes semântico-temporais descrito por Cardoso (2019). Esses métodos e os fluxos de trabalho deles derivados estão organizados em um único algoritmo em desenvolvimento, que é apresentado na Imagem 2 e na Tabela 1. Esta tabela se limita a um relato do algoritmo até a caixa 12 do fluxograma, que foi a parte utilizada nesta pesquisa.

O segundo método citado também é fundamentado na lei de Zipf (ZIPF, 1949; MORENO-SÁNCHEZ, 2016; WILLIAMS, 2016; KANWAL, 2017), que determina que a frequência de qualquer palavra em uma lista ordenada é inversamente proporcional à sua classificação na tabela de frequência. Esta frequência é dada por $\mathrm{f}(\mathrm{n})=\mathrm{K} / \mathrm{n}$ ', onde $\mathrm{K}$ é uma constante. Uma palavra é menos relevante em um corpus, quanto mais avançada é sua posição no ranking. A maioria das palavras tem uma frequência muito baixa e desempenha um papel irrelevante. A diminuição da relevância de cada palavra na lista ordenada é frequentemente logarítmica, então as primeiras palavras mais usadas de um corpus são sempre relevantes e por vezes suficientes para estabelecer sua síntese. A contagem de palavras não é apenas relevante para o primeiro tratamento das fontes na pesquisa histórica, mas uma ferramenta essencial para deslegitimar a especulação histórica sem qualquer fundamento imposta ao campo por mero poder político. 


\section{Imagem 2 - Fluxograma metahistórico.}

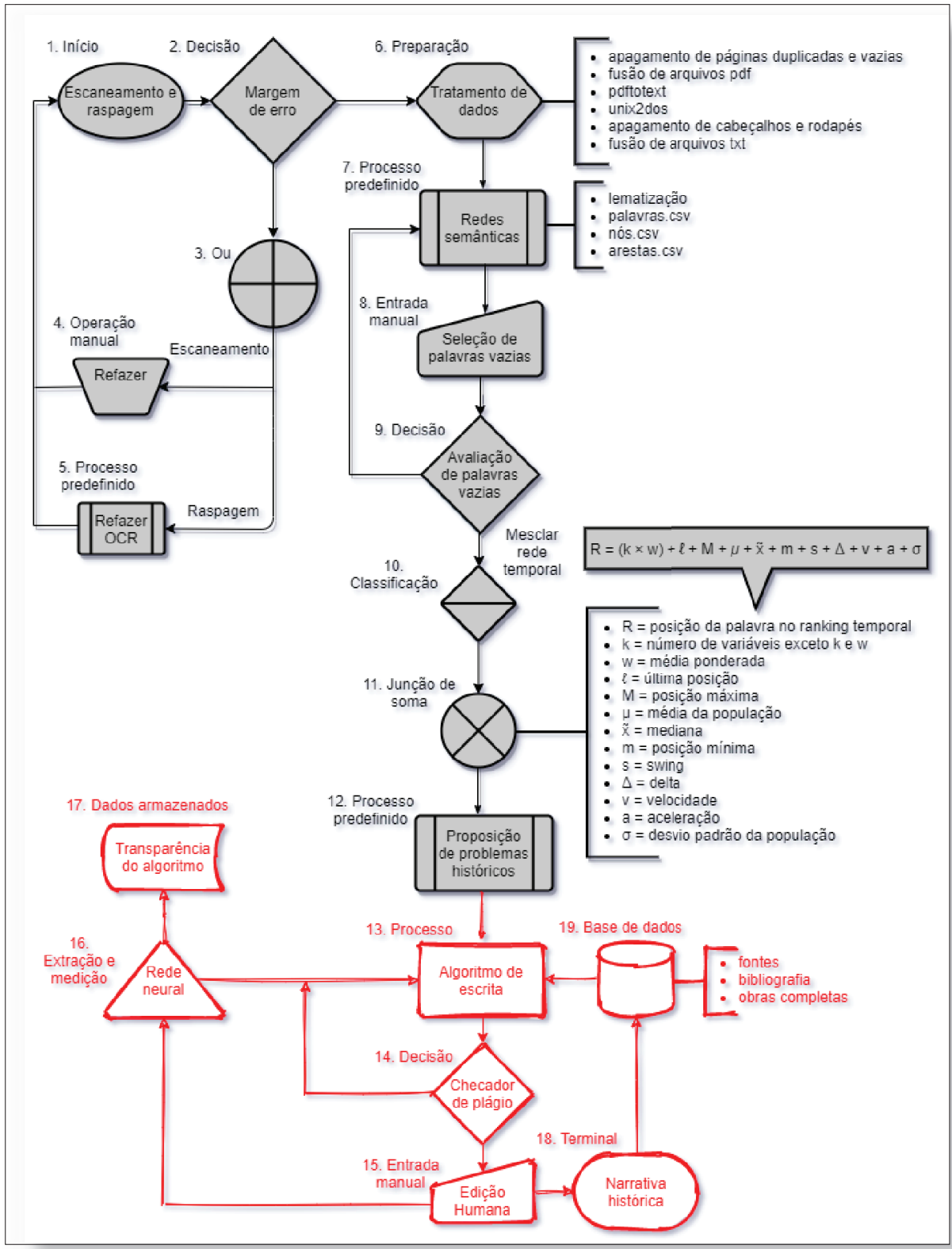

Fonte: Elaboração dos autores. 
O segundo método citado também se utiliza da equação $\mathrm{R}=(\mathrm{k} \times \mathrm{w})+\ell$ $+\mathrm{M}+\mu+\tilde{\mathrm{x}}+\mathrm{m}+\mathrm{s}+\Delta+\mathrm{v}+\mathrm{a}+\sigma$, criada pelos dois primeiros autores, para reunir redes semânticas sincrônicas numa rede semântico-temporal que nos permite problematizar a fenomenologia da flutuação de cada palavra ao longo do tempo na lista de palavras mais usadas. $\mathrm{O}$ algoritmo utilizado nesta pesquisa foi programado com base nessa equação para analisar cinco fenômenos semântico-temporais distintos: ascensão, queda, estabilidade, ascensão repentina e aparecimento repentino. O significado estatístico de cada um desses fenômenos encontra-se detalhado na segunda linha da Tabela 4 e da Tabela 6.

Tabela 1 - Descrição das funções das 12 primeiras caixas do fluxograma.

\begin{tabular}{|c|l|}
\hline Caixa & \multicolumn{1}{c|}{ Função } \\
\hline 1 & $\begin{array}{l}\text { Coleta de fontes digitalizando livros impressos com alguma ajuda humana ou } \\
\text { copiando dados automaticamente da internet. A maneira mais fácil, barata e eficaz } \\
\text { de digitalizar um livro, com melhores resultados em reconhecimento ótico de } \\
\text { caracteres (OCR), é cortar suas lombadas e digitalizá-lo em um arquivo em formato } \\
\text { pdf como folhas avulsas. O primeiro problema com a obtenção de fontes digitais é } \\
\text { retirá-las da internet. Como muitas plataformas acadêmicas têm proteção contra } \\
\text { bots, o que é estranho e sintomático, a coleta de dados requer o uso de algumas } \\
\text { interfaces de programação de aplicativos (APIs) para contornar essas proteços nas } \\
\text { plataformas onde as fontes são armazenadas. Depois de contornar a proteção, o } \\
\text { segundo problema é lidar com arquivos digitais com péssimo reconhecimento ótico } \\
\text { de caracteres (OCR) porque eles foram feitos há muito tempo, quando essa tecnologia } \\
\text { era incipiente. Portanto, precisamos excluir os OCRs e gerá-los novamente com } \\
\text { tecnologia melhor. }\end{array}$ \\
\hline 2 & $\begin{array}{l}\text { Cálculo da margem de erro do reconhecimento ótico de caracteres (OCR) usado para } \\
\text { digitalizar as fontes. Usamos uma ferramenta de verificação ortográfica para saber a } \\
\text { margem de erro da digitalização das fontes contando quantas palavras são detectadas } \\
\text { como erradas pela ferramenta e comparando essa quantidade com o número de } \\
\text { palavras em todo o texto. Se a margem de erro for inferior a 1\%, os dados são enviados } \\
\text { para a caixa } 6 \text { do fluxograma, "Preparação: Tratamento de dados". Se a margem de } \\
\text { erro for superior a 1\%, os dados são enviados para a caixa } 3 \text { do fluxograma, "Ou”. }\end{array}$ \\
\hline 3 & $\begin{array}{l}\text { A função "Ou” separa as fontes escaneadas, enviadas para a caixa } 4 \text { do fluxograma, } \\
\text { "Operação manual: Refazer", das fontes raspadas, enviadas para a caixa } 5 \text { do } \\
\text { fluxograma, "Processo predefinido: Refazer OCR". }\end{array}$ \\
\hline $\begin{array}{l}\text { Operação manual para refazer a digitalização das fontes impressas com margem de } \\
\text { erro superior a 1\%. Não é possível fazer nada automaticamente se a digitalização de } \\
\text { uma fonte impressa foi mal feita, e esta é a única operação manual neste fluxograma } \\
\text { que não pode ser substituída por uma automática. }\end{array}$ \\
\hline
\end{tabular}




\begin{tabular}{|c|c|}
\hline 5 & $\begin{array}{l}\text { O processo predefinido para refazer o reconhecimento ótico de caracteres (OCR) se } \\
\text { uma fonte de arquivo em formato pdf apresenta uma margem de erro maior que } 1 \% \text {. } \\
\text { Nesse caso, podemos corrigir o problema automaticamente excluindo o OCR antigo } \\
\text { e criando um novo. }\end{array}$ \\
\hline 6 & $\begin{array}{l}\text { Preparação das fontes através do tratamento de dados, excluindo páginas duplicadas } \\
\text { e páginas inúteis (como anúncios e índices), mesclando arquivos em formato pdf } \\
\text { (para combinar muitos artigos em apenas um arquivo de edição completo), } \\
\text { convertendo esses arquivos em formato txt, excluindo cabeçalhos e rodapés de cada } \\
\text { página (a repetição das mesmas palavras em muitas páginas pode distorcer a contagem } \\
\text { final de palavras e todos os resultados) e, finalmente, mesclar arquivos em formato } \\
\text { txt para criar os corpora de cada período selecionado. }\end{array}$ \\
\hline 7 & $\begin{array}{l}\text { Processo predefinido para criar uma rede semântica para cada corpus. Esse processo } \\
\text { começa com a lematização dos corpora, que envolve a diferenciação de substantivos } \\
\text { e verbos escritos com as mesmas palavras e a divisão de palavras compostas. Em } \\
\text { seguida, as palavras de cada corpus são contadas e classificadas no arquivo words.csv, } \\
\text { os nós formados por essas palavras são identificados por um número de identidade } \\
\text { no arquivo nodes.csv, e esses números de identidade são usados para estabelecer as } \\
\text { arestas entre as palavras. }\end{array}$ \\
\hline 8 & $\begin{array}{l}\text { Entrada manual das palavras vazias (stopwords), que são as palavras não relevantes } \\
\text { para a pesquisa (como o, de, e, ser, para etc.) e eventualmente também as palavras } \\
\text { usadas no título das fontes ou do campo de pesquisa. O algoritmo pode ser carregado } \\
\text { com uma lista genérica de palavras vazias e pular esta etapa manual, filtrando } \\
\text { automaticamente a classificação das palavras mais usadas com sua lista padrão de } \\
\text { palavras vazias, mas a entrada manual fornece melhor qualidade até que uma } \\
\text { inteligência artificial específica seja desenvolvida para definir que palavras vazias } \\
\text { estão em cada corpus. }\end{array}$ \\
\hline 9 & $\begin{array}{l}\text { Avaliação se ainda existem palavras vazias entre as palavras do arquivo words.csv. } \\
\text { Em caso afirmativo, a lista de palavras é enviada de volta em ciclo para a caixa } 7 \text { do } \\
\text { fluxograma, "Processo predefinido: Redes semânticas"; caso contrário, ele é enviado } \\
\text { para a caixa } 10 \text { do fluxograma, "Classificação: Mesclar rede temporal". }\end{array}$ \\
\hline 10 & Mescla das redes semânticas de cada período em uma rede semântico-temporal. \\
\hline 11 & $\begin{array}{l}\text { Utilização da equação temporalizadora } \mathrm{R}=(\mathrm{k} \times \mathrm{w})+\ell+\mathrm{M}+\mu+\tilde{\mathrm{x}}+\mathrm{m}+\mathrm{s}+\Delta+\mathrm{v} \\
+\mathrm{a}+\sigma \text {, descrita na caixa } 11 \text { do fluxograma, "Junção de soma", para avaliar o fenômeno } \\
\text { de flutuação de cada palavra ao longo do tempo na lista de palavras mais usadas. }\end{array}$ \\
\hline 12 & $\begin{array}{l}\text { Proposição de problemas históricos com base em inteligência natural fundamentada } \\
\text { na composição de variáveis estatísticas pela equação temporalizadora. }\end{array}$ \\
\hline
\end{tabular}

Fonte: Elaboração dos autores. 
Uma descrição detalhada dos fluxos de trabalho desta pesquisa pode ser vista no arquivo _workflow.pdf, localizado na raiz da pasta de arquivos do projeto hospedado na Open Science Framework (https://osf.io/bepqd/files/). Uma tradução deste arquivo encontra-se abaixo na Tabela 2.

Tabela 2 - Fluxo de trabalho desta pesquisa.

Fluxo de trabalho (versão 01 - 30/05/2021)

Todo este fluxo de trabalho executa arquivos Python em terminal Linux ou Google Apps Scripts em arquivos Google Planilhas.

Todas as etapas sujeitas a viés neste fluxo de trabalho estão em fonte vermelha.

\begin{tabular}{|c|c|c|}
\hline 1 & $\begin{array}{l}\text { Baixar todos os arquivos pdf } \\
\qquad\left(01 \_ \text {pdf }\right)\end{array}$ & $\begin{array}{l}\text { HH (2012-2020): https://anpuh.org.br/index. } \\
\text { php/revistas-anpuh/revista-historia-hoje-i } \\
\text { RBH (2012-2020): https://www.scielo.br/scielo. } \\
\text { php?script=sci_issues\&pid=0102- } \\
\text { 0188\&lng=pt\&nrm=iso }\end{array}$ \\
\hline 2 & $\begin{array}{l}\text { Converter todos os arquivos } \\
\text { pdf para txt (01_pdf) }\end{array}$ & find -name ${ }^{*}$.pdf -exec pdftotext \{\}$\backslash$; \\
\hline 3 & $\begin{array}{l}\text { Mover todos os arquivos txt } \\
\text { para uma nova pasta } \\
\text { (01_pdf a 02_txt) }\end{array}$ & $\begin{array}{c}\mathrm{mv}^{*} . \mathrm{txt} \sim / 02 \_\mathrm{txt} / 2012 \\
\mathrm{mv}{ }^{*} . \mathrm{txt} \sim / 02 \_\mathrm{txt} / 2013 \\
\ldots\end{array}$ \\
\hline 4 & $\begin{array}{c}\text { Mesclar todos os arquivos txt } \\
\text { em corpora anuais } \\
\text { (03_annual_corpora) }\end{array}$ & $\begin{array}{l}\text { for } \mathrm{d} \text { in } \$(\text { seq } 20122020) \text {; } \\
\text { do cat } \$ \mathrm{~d} /{ }^{*}>\$ \text { d.txt } \text {; done }\end{array}$ \\
\hline 5 & $\begin{array}{l}\text { Mesclar todos os corpora } \\
\text { anuais em um corpus } \\
\text { completo } \\
\text { (04_full_corpus) }\end{array}$ & cat $^{*}$.txt $>$ fullcorpus.txt \\
\hline 6 & $\begin{array}{l}\text { Criar um arquivo words.csv, } \\
\text { selecionar palavras vazias } \\
\text { manualmente e salvar um } \\
\text { novo arquivo stopwords.csv } \\
\text { (05_stopwords) }\end{array}$ & /filter.py fullcorpus.txt fullcorpus \\
\hline 7 & $\begin{array}{c}\text { Criar nós, arestas e palavras, } \\
\text { arquivos filtrados com } \\
\text { palavras } \\
\text { irrelevantes (06_words) }\end{array}$ & $\begin{array}{l}\text { for year in \$(seq } 2012 \text { 2020); do / filter.py } \\
\quad \text { \$year.txt \$year -f stopwords.csv; done }\end{array}$ \\
\hline
\end{tabular}




\begin{tabular}{|c|c|c|}
\hline 8 & $\begin{array}{l}\text { Estabelecer fenômenos } \\
\text { semântico-temporais } \\
\text { (07_phenomenology) }\end{array}$ & $\begin{array}{c}\text { for linhas in } 2030405060708090100200 \\
250300400500 ; \text { do } \sim / \text { merge_words.py } \\
\text {--headers } \$ \text { (seq } 2012 \text { 2020) --files } 20^{*} \text { _words. } \\
\text { csv --lines } \$ \text { linhas > phenomenology_\$\{linhas\}. } \\
\text { csv; / phenomenology.py } \\
\text { phenomenology_\$\{linhas\}.csv > } \$\{\text { linhas }\} . t x t ; \\
\text { done }\end{array}$ \\
\hline 9 & $\begin{array}{l}\text { Converter todos os arquivos } \\
\text { txt para Google Docs }\end{array}$ & TXT to GOOGLEDOCS converter V4.gs \\
\hline 10 & $\begin{array}{l}\text { Tratamento macroscópico } \\
\text { (08_specific_words) }\end{array}$ & BATCH FILE SCANNER V5.gs \\
\hline
\end{tabular}

Fonte: Elaboração dos autores.

\section{TRATAMENTO DOS DADOS}

A Tabela 3 a seguir apresenta as palavras mais usadas na Revista História Hoje ao longo do tempo, desde seu surgimento e excetuando-se as palavras vazias, seguidas do número de vezes em que a palavra apareceu naquele corpus específico. A tabela destaca a célula de cada palavra em uma cor diferente, para facilitar a visualização dos seus fenômenos semântico-temporais. Apenas as primeiras 50 palavras do corpus completo são identificadas com uma cor de célula que se repete na mesma palavra quando ela aparece nas demais colunas. Palavras em branco na Tabela 3 indicam as que não estão entre as 50 primeiras no corpus completo. Por uma questão de espaço, apenas as primeiras 19 palavras do corpus completo e de cada corpora anual são mostradas na Tabela 3. Porém, a planilha completa com todas as 8442 palavras do corpus completo e todas as palavras dos corpora anuais pode ser vista no arquivo dataset/HH/07_ phenomenology/final_words.xlsx do projeto hospedado na Open Science Framework (https://osf.io/bepqd/files/). 
Tabela 3 - As 19 palavras mais usadas no corpus completo da RHHJ e nos corpora anuais, seguidas do número

de vezes em que cada uma delas aparece em cada corpus.

\begin{tabular}{|c|c|c|c|c|c|c|c|c|c|}
\hline $\begin{array}{c}\text { Corpus } \\
\text { completo }\end{array}$ & 2012 & 2013 & 2014 & 2015 & 2016 & 2017 & 2018 & 2019 & 2020 \\
\hline $\begin{array}{l}\text { história, } \\
23377\end{array}$ & $\begin{array}{l}\text { história, } \\
2044\end{array}$ & $\begin{array}{l}\text { história, } \\
2995\end{array}$ & $\begin{array}{l}\text { história, } \\
2081\end{array}$ & $\begin{array}{l}\text { história, } \\
2880\end{array}$ & $\begin{array}{l}\text { história, } \\
2501\end{array}$ & $\begin{array}{l}\text { história, } \\
2622\end{array}$ & $\begin{array}{l}\text { história, } \\
2039\end{array}$ & $\begin{array}{l}\text { história, } \\
3298\end{array}$ & $\begin{array}{l}\text { história, } \\
2917\end{array}$ \\
\hline $\begin{array}{l}\text { ensino, } \\
8816\end{array}$ & $\begin{array}{l}\text { indígena, } \\
1347\end{array}$ & $\begin{array}{l}\text { professor, } \\
1486\end{array}$ & $\begin{array}{l}\text { professor, } \\
918\end{array}$ & $\begin{array}{l}\text { ensino, } \\
1175\end{array}$ & $\begin{array}{l}\text { histórico, } \\
1146\end{array}$ & $\begin{array}{l}\text { histórico, } \\
1012\end{array}$ & $\begin{array}{l}\text { livro, } \\
773 \\
\end{array}$ & $\begin{array}{l}\text { histórico, } \\
1016\end{array}$ & $\begin{array}{l}\text { histórico, } \\
1244\end{array}$ \\
\hline $\begin{array}{l}\text { histórico, } \\
7544\end{array}$ & $\begin{array}{l}\text { escola, } \\
711\end{array}$ & $\begin{array}{l}\text { ensino, } \\
1197\end{array}$ & $\begin{array}{l}\text { ensino, } \\
846\end{array}$ & $\begin{array}{l}\text { professor, } \\
1127\end{array}$ & $\begin{array}{l}\text { ensino, } \\
1123\end{array}$ & $\begin{array}{l}\text { ensino, } \\
906\end{array}$ & $\begin{array}{l}\text { ensino, } \\
756\end{array}$ & $\begin{array}{l}\text { ensino, } \\
1004\end{array}$ & $\begin{array}{l}\text { ensino, } \\
1135\end{array}$ \\
\hline $\begin{array}{l}\text { professor, } \\
7423\end{array}$ & $\begin{array}{l}\text { brasil, } \\
695\end{array}$ & $\begin{array}{l}\text { histórico, } \\
712\end{array}$ & $\begin{array}{l}\text { poder, } \\
746\end{array}$ & $\begin{array}{l}\text { histórico, } \\
895\end{array}$ & $\begin{array}{l}\text { professor, } \\
895\end{array}$ & $\begin{array}{l}\text { poder, } \\
750\end{array}$ & $\begin{array}{l}\text { educação, } \\
686\end{array}$ & $\begin{array}{l}\text { público, } \\
913\end{array}$ & $\begin{array}{l}\text { professor, } \\
801\end{array}$ \\
\hline $\begin{array}{l}\text { poder, } \\
6199\end{array}$ & $\begin{array}{l}\text { poder, } \\
674\end{array}$ & $\begin{array}{l}\text { poder, } \\
694\end{array}$ & $\begin{array}{l}\text { curso, } \\
724\end{array}$ & $\begin{array}{l}\text { educação, } \\
722\end{array}$ & $\begin{array}{l}\text { educação, } \\
815\end{array}$ & $\begin{array}{l}\text { aluno, } \\
735\end{array}$ & $\begin{array}{l}\text { didático, } \\
568\end{array}$ & $\begin{array}{l}\text { poder, } \\
772\end{array}$ & $\begin{array}{l}\text { educação, } \\
733\end{array}$ \\
\hline $\begin{array}{l}\text { educação, } \\
5801\end{array}$ & $\begin{array}{l}\text { ensino, } \\
674\end{array}$ & $\begin{array}{l}\text { tempo, } \\
653\end{array}$ & $\begin{array}{l}\text { educação, } \\
657\end{array}$ & $\begin{array}{l}\text { curso, } \\
675\end{array}$ & $\begin{array}{l}\text { aluno, } \\
716\end{array}$ & $\begin{array}{l}\text { música, } \\
611\end{array}$ & $\begin{array}{l}\text { poder, } \\
564\end{array}$ & $\begin{array}{l}\text { professor, } \\
663\end{array}$ & $\begin{array}{l}\text { poder, } \\
704\end{array}$ \\
\hline $\begin{array}{l}\text { aluno, } \\
4548\end{array}$ & $\begin{array}{l}\text { brasileiro, } \\
645\end{array}$ & $\begin{array}{l}\text { educação, } \\
648\end{array}$ & $\begin{array}{l}\text { histórico, } \\
638\end{array}$ & $\begin{array}{l}\text { escola, } \\
598\end{array}$ & $\begin{array}{l}\text { poder, } \\
711\end{array}$ & $\begin{array}{l}\text { professor, } \\
601\end{array}$ & $\begin{array}{l}\text { professor, } \\
537\end{array}$ & $\begin{array}{l}\text { educação, } \\
636\end{array}$ & $\begin{array}{l}\text { direito, } \\
643\end{array}$ \\
\hline $\begin{array}{l}\text { escola, } \\
4125\end{array}$ & $\begin{array}{l}\text { educação, } \\
596\end{array}$ & $\begin{array}{l}\text { livro, } \\
628 \\
\end{array}$ & $\begin{array}{l}\text { hoje, } \\
503\end{array}$ & $\begin{array}{l}\text { poder, } \\
584\end{array}$ & $\begin{array}{l}\text { didático, } \\
505\end{array}$ & $\begin{array}{l}\text { aula, } \\
555 \\
\end{array}$ & $\begin{array}{l}\text { direito, } \\
489 \\
\end{array}$ & $\begin{array}{l}\text { social, } \\
559\end{array}$ & $\begin{array}{l}\text { humano, } \\
633\end{array}$ \\
\hline $\begin{array}{l}\text { hoje, } \\
4108\end{array}$ & $\begin{array}{l}\text { negro, } \\
491\end{array}$ & $\begin{array}{l}\text { aluno, } \\
614\end{array}$ & $\begin{array}{l}\text { memória, } \\
488\end{array}$ & $\begin{array}{l}\text { aluno, } \\
571\end{array}$ & $\begin{array}{l}\text { trabalho, } \\
486\end{array}$ & $\begin{array}{l}\text { brasil, } \\
508\end{array}$ & $\begin{array}{l}\text { histórico, } \\
477\end{array}$ & $\begin{array}{l}\text { escola, } \\
511\end{array}$ & $\begin{array}{l}\text { aprendizagem, } \\
590\end{array}$ \\
\hline $\begin{array}{l}\text { brasil, } \\
3949\end{array}$ & $\begin{array}{l}\text { índio, } \\
484\end{array}$ & $\begin{array}{l}\text { didático, } \\
603\end{array}$ & $\begin{array}{l}\text { aluno, } \\
487\end{array}$ & $\begin{array}{l}\text { escolar, } \\
562\end{array}$ & $\begin{array}{l}\text { docente, } \\
479\end{array}$ & $\begin{array}{l}\text { tempo, } \\
471\end{array}$ & $\begin{array}{l}\text { indígena, } \\
469\end{array}$ & $\begin{array}{l}\text { brasil, } \\
505\end{array}$ & $\begin{array}{l}\text { brasil, } \\
548\end{array}$ \\
\hline $\begin{array}{l}\text { social, } \\
3801\end{array}$ & $\begin{array}{l}\text { hoje, } \\
472\end{array}$ & $\begin{array}{l}\text { social, } \\
535\end{array}$ & $\begin{array}{l}\text { museu, } \\
445\end{array}$ & $\begin{array}{l}\text { tempo, } \\
437\end{array}$ & $\begin{array}{l}\text { hoje, } \\
454\end{array}$ & $\begin{array}{l}\text { hoje, } \\
445\end{array}$ & $\begin{array}{l}\text { escola, } \\
466\end{array}$ & $\begin{array}{l}\text { passado, } \\
466\end{array}$ & $\begin{array}{l}\text { aula, } \\
512 \\
\end{array}$ \\
\hline $\begin{array}{l}\text { tempo, } \\
3637\end{array}$ & $\begin{array}{l}\text { cultura, } \\
452\end{array}$ & $\begin{array}{l}\text { escola, } \\
525\end{array}$ & $\begin{array}{l}\text { público, } \\
401\end{array}$ & $\begin{array}{l}\text { hoje, } \\
427\end{array}$ & $\begin{array}{l}\text { social, } \\
431\end{array}$ & $\begin{array}{l}\text { brasileiro, } \\
442\end{array}$ & $\begin{array}{l}\text { social, } \\
446\end{array}$ & $\begin{array}{l}\text { hoje, } \\
457\end{array}$ & $\begin{array}{l}\text { narrativa, } \\
489\end{array}$ \\
\hline $\begin{array}{l}\text { didático, } \\
3474\end{array}$ & $\begin{array}{l}\text { histórico, } \\
404\end{array}$ & $\begin{array}{l}\text { hoje, } \\
480\end{array}$ & $\begin{array}{l}\text { ano, } \\
376\end{array}$ & $\begin{array}{l}\text { social, } \\
402\end{array}$ & $\begin{array}{l}\text { livro, } \\
425\end{array}$ & $\begin{array}{l}\text { livro, } \\
394\end{array}$ & $\begin{array}{l}\text { político, } \\
435\end{array}$ & $\begin{array}{l}\text { ano, } \\
412\end{array}$ & $\begin{array}{l}\text { tempo, } \\
465\end{array}$ \\
\hline $\begin{array}{l}\text { livro, } \\
3448\end{array}$ & $\begin{array}{l}\text { povo, } \\
400\end{array}$ & $\begin{array}{l}\text { curso, } \\
473\end{array}$ & $\begin{array}{l}\text { escola, } \\
375\end{array}$ & $\begin{array}{l}\text { ano, } \\
390\end{array}$ & $\begin{array}{l}\text { pesquisa, } \\
389\end{array}$ & $\begin{array}{l}\text { novo, } \\
386\end{array}$ & $\begin{array}{l}\text { brasil, } \\
429\end{array}$ & $\begin{array}{l}\text { tempo, } \\
403\end{array}$ & $\begin{array}{l}\text { aluno, } \\
454\end{array}$ \\
\hline $\begin{array}{l}\text { aula, } \\
3356\end{array}$ & $\begin{array}{l}\text { professor, } \\
395\end{array}$ & $\begin{array}{l}\text { escolar, } \\
452\end{array}$ & $\begin{array}{l}\text { pesquisa, } \\
371\end{array}$ & $\begin{array}{l}\text { avaliação, } \\
385\end{array}$ & $\begin{array}{l}\text { aula, } \\
389\end{array}$ & $\begin{array}{l}\text { público, } \\
364\end{array}$ & $\begin{array}{l}\text { hoje, } \\
427\end{array}$ & $\begin{array}{l}\text { memória, } \\
384\end{array}$ & $\begin{array}{l}\text { hoje, } \\
443\end{array}$ \\
\hline $\begin{array}{l}\text { ano, } \\
3223\end{array}$ & $\begin{array}{l}\text { novo, } \\
389\end{array}$ & $\begin{array}{l}\text { ano, } \\
439\end{array}$ & $\begin{array}{l}\text { social, } \\
352\end{array}$ & $\begin{array}{l}\text { pesquisa, } \\
385\end{array}$ & $\begin{array}{l}\text { cultura, } \\
352\end{array}$ & $\begin{array}{l}\text { passado, } \\
352\end{array}$ & $\begin{array}{l}\text { humano, } \\
405\end{array}$ & $\begin{array}{l}\text { pesquisa, } \\
348\end{array}$ & $\begin{array}{l}\text { escolar, } \\
433\end{array}$ \\
\hline $\begin{array}{l}\text { escolar, } \\
3057\end{array}$ & $\begin{array}{l}\text { tempo, } \\
385\end{array}$ & $\begin{array}{l}\text { presente, } \\
415\end{array}$ & $\begin{array}{l}\text { didático, } \\
347\end{array}$ & $\begin{array}{l}\text { aula, } \\
385\end{array}$ & $\begin{array}{l}\text { escola, } \\
349\end{array}$ & $\begin{array}{l}\text { trabalho, } \\
346\end{array}$ & $\begin{array}{l}\text { historiar, } \\
384\end{array}$ & $\begin{array}{l}\text { aluno, } \\
342\end{array}$ & $\begin{array}{l}\text { brasileiro, } \\
426\end{array}$ \\
\hline $\begin{array}{l}\text { público, } \\
3033\end{array}$ & $\begin{array}{l}\text { cultural, } \\
349\end{array}$ & $\begin{array}{l}\text { trabalho, } \\
409\end{array}$ & $\begin{array}{l}\text { trabalho, } \\
336\end{array}$ & $\begin{array}{l}\text { docente, } \\
376\end{array}$ & $\begin{array}{l}\text { consciência, } \\
349\end{array}$ & $\begin{array}{l}\text { social, } \\
340\end{array}$ & $\begin{array}{l}\text { aluno, } \\
370\end{array}$ & $\begin{array}{l}\text { historiador, } \\
339\end{array}$ & $\begin{array}{l}\text { presente, } \\
415\end{array}$ \\
\hline $\begin{array}{l}\text { trabalho, } \\
2981\end{array}$ & $\begin{array}{l}\text { africano, } \\
342\end{array}$ & $\begin{array}{l}\text { disciplina, } \\
406\end{array}$ & $\begin{array}{l}\text { brasil, } \\
334\end{array}$ & $\begin{array}{l}\text { disciplina, } \\
355\end{array}$ & $\begin{array}{l}\text { presente, } \\
313\end{array}$ & $\begin{array}{l}\text { presente, } \\
339\end{array}$ & $\begin{array}{l}\text { aula, } \\
365\end{array}$ & $\begin{array}{l}\text { político, } \\
331\end{array}$ & $\begin{array}{l}\text { pesquisa, } \\
402\end{array}$ \\
\hline
\end{tabular}

Fonte: Elaboração dos autores.

O fato de a Tabela 3 ter a palavra "história" em sua primeira linha é irrelevante, já que esta palavra é o nome do campo e usada no título da revista que compõe o corpus. Por essas duas razões, nós poderíamos ter optado por incluir a palavra "história" entre as palavras vazias. Não o fizemos por razões didáticas, já que este artigo tem também a função de servir como uma introdução à ciên- 
cia aberta para historiadores. Esta escolha explicita que a definição da lista de palavras vazias é um dos passos sujeitos a viés no fluxo de trabalho desta pesquisa, por isso marcado em cor de fonte vermelha no arquivo _workflow.pdf que se encontra na raiz da pasta de arquivos do projeto hospedado na Open Science Framework (https://osf.io/bepqd/files/). Nesse mesmo endereço, as palavras vazias podem ser encontradas nos arquivos dataset/HH/05_stopwords/HH_stopwords.csv e dataset/RBH/05_stopwords/RBH_stopwords.csv. Elas foram criadas pelo apagamento das palavras relevantes dos arquivos dataset/ HH/04_full_corpus/HH_fullcorpus_words.csv e dataset/RBH/04_full_corpus/ RBH_fullcorpus_words.csv. Este apagamento é uma escolha enviesada que impacta o resultado da pesquisa, mas isso não é visto na ciência aberta como um problema. Não há na ciência aberta uma crença na objetividade absoluta da ciência que caracteriza o cientismo. Ciência aberta não é uma ciência sem viés. Toda ciência é enviesada, inclusive as ciências duras (IOANNIDIS, 2005). Em vez de se esforçar para esconder seus vieses, como faz a ciência normal (KUHN, 1996, p. 10; ANDERSEN, 2006, p. 5, 69-72; MARCUM, 2012, p. 42), a ciência aberta transforma em protocolo a explicitação de todos os seus vieses. Uma pesquisa aberta não é reprodutível por ser objetiva, mas por deixar transparentes todas as escolhas subjetivas feitas ao longo do fluxo de trabalho.

A segunda palavra mais usada no corpus completo da Revista História Hoje, apresentado na Tabela 3, é a palavra "ensino", que flutua entre a segunda, a terceira e a sexta posições ao longo do tempo. Esse fenômeno é compreensível pelo fato de a revista ter se especializado no ensino de História. A terceira palavra mais usada no corpus completo da Revista História Hoje é "histórico", que eventualmente poderia ser considerada uma palavra vazia. As palavras seguintes são "professor" (que flutua entre a $2^{\text {a }}$ e a $15^{\mathrm{a}}$ posição), "poder" ( $4^{\mathrm{a}}$ à $8^{\mathrm{a}}$ posição), educação ( $4^{\mathrm{a}}$ à $24^{\mathrm{a}}$ posição), "aluno" (5ª à $33^{\mathrm{a}}$ posição) e “escola" (3a à 27a). Também é interessante observar por que as palavras "negro", "índio", "povo", “africano", "museu”, “avaliação”, "consciência”, "música”, "historiar" e "historiador" aparecem em branco entre as primeiras palavras, ou seja, aparecem de forma significativa apenas em um dos corpora anuais.

A observação da flutuação temporal das diversas palavras na Tabela 3 permite muitas análises a olho nu que extrapolam o caráter introdutório deste artigo. Nosso objetivo não é realizar uma análise, mas fornecer dados que possibilitem uma infinidade de análises aos leitores da Revista História Hoje. 
Cada olho nu poderá enxergar distintos fenômenos na Tabela 3, dependendo de sua formação, área de atuação e interesses específicos. Também é possível aprofundar a análise a olho nu observando a planilha completa com todas as 8442 palavras do corpus completo no arquivo dataset/HH/07_phenomenology/final_words.xlsx do projeto hospedado na Open Science Framework (https:// osf.io/bepqd/files/).

Para além de tudo que é possível analisar a olho nu na Tabela 3, desenvolvemos uma inteligência natural que analisa os dados dessa tabela e identifica fenômenos semântico-temporais em trechos selecionados das listas de palavras mais usadas, cujos resultados são apresentados a seguir na Tabela 4. Essa inteligência natural se utiliza das variáveis estatísticas identificadas na segunda linha da Tabela 4 para classificar cada palavra diante dos fenômenos de ascensão (a palavra passa a ser cada vez mais usada nos corpora de cada período), queda (a palavra passa a ser cada vez menos usada nos corpora de cada período), estabilidade (a palavra é usada em quantidades próximas nos corpora de todos os períodos), ascensão repentina (a palavra já estava entre as mais usadas nos primeiros períodos e passa a ser ainda mais usada nos últimos períodos) e aparecimento repentino (a palavra sequer estava entre as mais usadas nos primeiros períodos, mas aparece entre elas nos últimos períodos). A primeira coluna da Tabela 4 indica quantas palavras mais usadas foram consideradas para a definição dos fenômenos descritos nas cinco colunas seguintes. As células em branco na Tabela 4 indicam que o fenômeno descrito naquela coluna não se apresenta naquela linha, ou seja, o fenômeno não se apresenta considerando a quantidade de palavras mais usadas definida naquela linha.

Por uma questão de espaço, não nos aprofundaremos em todas as palavras que aparecem na Tabela 4, mas apenas destacaremos dentre os fenômenos que podem ser observados nela: a ascensão das palavras "aula" (por se repetir em cinco linhas da tabela) e "consciência" (por se repetir em duas colunas da tabela), a queda das palavras "novo" e "antigo" (pela repetição da primeira em duas linhas e pelo fato de a segunda ser antônimo da primeira e de ambas aparecerem em extremos opostos da tabela), a ascensão repentina das palavras "direito" e "humano" (por se repetirem em várias linhas da tabela) e o aparecimento repentino da palavra "gênero".

Para observar mais de perto essas palavras selecionadas na Tabela 4, utilizamos dois códigos em Google Apps Script disponíveis na pasta "code” do 
projeto hospedado na Open Science Framework (https://osf.io/bepqd/files/). O código "TXT to GOOGLEDOCS converter V4.gs" foi utilizado para converter os corpora da RHHJ (https://drive.google.com/drive/u/0/folders/1psIC_ IwfYyO216boCBWMNKoWT4pzvWzW) e da RBH (https://drive.google.com/ drive/u/0/folders/1pe4HrN30kxPXUgx30EkYPDUbHQ-I8bJP) do formato txt para o formato Google Docs. Em seguida, utilizamos o código "BATCH FILE SCANNER V5.gs" para criar planilhas que listam todos os parágrafos em que uma palavra específica aparece, criando uma aba para cada corpus anual e disponibilizando ao lado de cada parágrafo o nome arquivo em que ele se encontra e um link direto para este arquivo. $\mathrm{O}$ uso desses dois códigos permite transitar da observação microscópica da rede semântico-temporal para uma observação macroscópica ou a olho nu dos mesmos fenômenos. As planilhas criadas pelo código "BATCH FILE SCANNER V5.gs" permitem observar rapidamente os diversos contextos em que uma palavra aparece em cada corpus e elaborar hipóteses mais precisas sobre os fenômenos nos quais ela está inserida. As planilhas criadas por este último código para cada uma das palavras listadas no parágrafo anterior (aula, consciência, novo, antigo, direito, humano e gênero) encontram-se disponíveis em formato xlsx na pasta "dataset/ HH/08_specific_words" do projeto hospedado na Open Science Framework (https://osf.io/bepqd/files/).

Dentre as palavras em ascensão, "aula" passou de 83 menções em 2012 para 230 menções em 2020 e "consciência” passou de 17 menções em 2012 para 100 menções em 2020, o que pode ser conferido nos arquivos xlsx citados no parágrafo anterior. As hipóteses para esses fenômenos são o crescimento da preocupação da área de ensino de História com o lugar da sala de aula e a recepção no Brasil do conceito alemão de Geschichtsbewusstsein. Dentre as palavras em queda, "novo" passou de 84 menções em 2012 para 37 menções em 2020 e “antigo" passou de 29 menções em 2012 para 5 menções em 2020. Observando os arquivos xlsx com todas as menções a cada uma dessas palavras, não conseguimos elaborar uma hipótese para esses dois fenômenos, o que demandaria uma análise macroscópica. Dentre as palavras que apresentaram ascensão repentina, "direito" passou de 12 menções em 2015 (ano em que teve o menor número de menções) para 62 menções em 2020 e "humano" passou de 7 menções em 2012 (ano em que teve o menor número de menções) para 35 menções em 2020. Nossa hipótese inicial era a de que essa flutuação correspondia à da ex- 
pressão "direitos humanos", mas observando o arquivo "HH direitos humanos. xlsx" percebemos que não há relação entre a flutuação dessa expressão e das duas palavras que a compõem. Formulamos a hipótese de que a ascensão repentina dessas duas palavras poderia estar relacionada aos temas específicos privilegiados nos números em que essa ascensão ocorre. Dentre as palavras que apresentaram aparecimento repentino, "gênero" passou de 28 menções em 2016 para 103 menções em 2017, período em que ocorreu o aparecimento repentino. Nossa hipótese inicial era a de que isso poderia estar relacionado a um crescimento da relevância dos estudos de gênero, mas ao analisarmos o arquivo "HH gênero. xlsx", percebemos que a palavra gênero está relacionada sobretudo ao gênero musical, por conta do tema privilegiado pela revista em 2017.

\section{Tabela 4 - Fenomenologia semântico-temporal das palavras mais usadas na RHHJ.}

\begin{tabular}{|c|c|c|c|c|c|}
\hline & Ascensão & Queda & Estabilidade & $\begin{array}{l}\text { Ascensão } \\
\text { repentina }\end{array}$ & $\begin{array}{c}\text { Aparecimento } \\
\text { repentino }\end{array}$ \\
\hline Palavras & $\begin{array}{l}\text { 1. Como explicar } \\
\text { a ascensão da(s) } \\
\text { palavra(s) x, y...? } \\
\text { - presente em } \\
\text { todos os períodos } \\
\text { (min }>0) \text {; } \\
\text { - termina mais alto } \\
\text { que começou } \\
\text { (swing e delta } \\
\text { positivos); } \\
\text { - começa entre as } \\
\text { 50\% últimas } \\
\text { palavras ( } 1^{\circ} \text { valor } \\
\text { de data }<\text { metade } \\
\text { do no de itens); } \\
\text { - termina entre as } \\
\text { palavras do } \\
\text { primeiro quarto } \\
\text { do ranking } \\
\text { (primeiras } 25 \%) \text {. }\end{array}$ & $\begin{array}{l}\text { 2. Como } \\
\text { explicar a queda } \\
\text { da(s) palavra(s) } \\
\text { x, y...? } \\
\text { - presente em } \\
\text { todos os } \\
\text { períodos (min } \\
>0) ; \\
\text { - termina mais } \\
\text { baixo que } \\
\text { começou } \\
\text { (swing e delta } \\
\text { negativos); } \\
\text { - começa entre } \\
\text { as } 50 \% \\
\text { primeiras } \\
\text { palavras (10 } \\
\text { valor de data > } \\
\text { metade do no } \\
\text { de itens); } \\
\text { - termina entre } \\
\text { as palavras do } \\
\text { último quarto } \\
\text { do ranking } \\
\text { (últimas } 25 \% \text { ). }\end{array}$ & $\begin{array}{l}\text { 3. Por que a(s) } \\
\text { palavra(s) } \mathbf{x}, \mathbf{y} . . \\
\text { é (são) } \\
\text { estável(is) na } \\
\text { primeira } \\
\text { metade das } \\
\text { palavras mais } \\
\text { usadas? } \\
\text { - presente em } \\
\text { todos os } \\
\text { períodos (min } \\
>0 \text { ); } \\
\text { - stdev <2.5; } \\
\text { - termina entre } \\
\text { as } 50 \% \\
\text { primeiras } \\
\text { palavras } \\
\text { (último valor } \\
\text { de data > } \\
\text { metade do no } \\
\text { de itens). }\end{array}$ & $\begin{array}{l}\text { 4. Como } \\
\text { explicar a } \\
\text { ascensão } \\
\text { repentina da(s) } \\
\text { palavra(s) x, } \\
\text { y...? } \\
\text { - presente em } \\
\text { um dos dois } \\
\text { últimos } \\
\text { períodos (sem } \\
0 \text { no data nos } \\
\text { dois últimos } \\
\text { períodos); } \\
\text { - termina entre } \\
\text { as } 25 \% \\
\text { primeiras } \\
\text { palavras; } \\
\text { •swing e delta > } \\
75 \% \text {. }\end{array}$ & $\begin{array}{l}\text { 5. Como } \\
\text { explicar o } \\
\text { surgimento } \\
\text { repentino da(s) } \\
\text { palavra(s) } \mathrm{x}, \\
\text { y...? } \\
\text { - presente } \\
\text { apenas nos } \\
\text { períodos da } 2^{\mathrm{a}} \\
\text { metade (sem } 0 \\
\text { no data na } 2^{\mathrm{a}} \\
\text { metade e com } 0 \\
\text { na } 1^{\mathrm{a}} \text { metade); } \\
\text { - min }=0 .\end{array}$ \\
\hline 20 & professor histórico & & $\begin{array}{l}\text { história ensino } \\
\text { poder }\end{array}$ & & \\
\hline
\end{tabular}




\begin{tabular}{|c|c|c|c|c|c|}
\hline 30 & & escola & $\begin{array}{l}\text { história ensino } \\
\text { poder hoje }\end{array}$ & direito humano & \\
\hline 40 & & & $\begin{array}{l}\text { história ensino } \\
\text { poder hoje }\end{array}$ & $\begin{array}{l}\text { direito humano } \\
\text { aprendizagem }\end{array}$ & \\
\hline 50 & & novo & $\begin{array}{l}\text { história ensino } \\
\text { poder hoje }\end{array}$ & $\begin{array}{l}\text { direito aula } \\
\text { humano } \\
\text { aprendizagem } \\
\text { narrativa }\end{array}$ & \\
\hline 60 & aluno aula & novo & $\begin{array}{l}\text { história ensino } \\
\text { poder hoje }\end{array}$ & $\begin{array}{l}\text { aula humano } \\
\text { aprendizagem } \\
\text { narrativa }\end{array}$ & \\
\hline 70 & aula presente & & $\begin{array}{l}\text { história ensino } \\
\text { poder hoje }\end{array}$ & $\begin{array}{l}\text { humano } \\
\text { aprendizagem } \\
\text { narrativa }\end{array}$ & \\
\hline 80 & aula presente & cultural & $\begin{array}{l}\text { história ensino } \\
\text { poder hoje }\end{array}$ & $\begin{array}{l}\text { humano } \\
\text { aprendizagem } \\
\text { narrativa }\end{array}$ & \\
\hline 90 & $\begin{array}{c}\text { aula } \\
\text { aprendizagem }\end{array}$ & & $\begin{array}{l}\text { história ensino } \\
\text { poder hoje }\end{array}$ & $\begin{array}{l}\text { humano } \\
\text { aprendizagem } \\
\text { narrativa } \\
\text { estudante }\end{array}$ & debate \\
\hline 100 & $\begin{array}{l}\text { aula aprendizagem } \\
\text { estudante }\end{array}$ & & $\begin{array}{l}\text { história ensino } \\
\text { poder hoje }\end{array}$ & $\begin{array}{l}\text { humano } \\
\text { aprendizagem } \\
\text { narrativa } \\
\text { estudante }\end{array}$ & \\
\hline 200 & $\begin{array}{l}\text { humano narrativa } \\
\text { disciplina sujeito } \\
\text { conceito }\end{array}$ & & $\begin{array}{l}\text { história ensino } \\
\text { poder hoje }\end{array}$ & & gênero \\
\hline 250 & $\begin{array}{l}\text { docente narrativa } \\
\text { disciplina }\end{array}$ & $\begin{array}{l}\text { comunidade } \\
\text { mudança }\end{array}$ & $\begin{array}{l}\text { história ensino } \\
\text { poder hoje }\end{array}$ & & gênero \\
\hline 300 & $\begin{array}{l}\text { docente disciplina } \\
\text { desenvolvimento }\end{array}$ & & $\begin{array}{l}\text { história ensino } \\
\text { poder hoje }\end{array}$ & $\begin{array}{l}\text { consciência } \\
\text { rüsen }\end{array}$ & gênero \\
\hline 400 & $\begin{array}{l}\text { metodologia } \\
\text { pensamento } \\
\text { metodológico }\end{array}$ & $\begin{array}{l}\text { ambiente } \\
\text { publicar }\end{array}$ & $\begin{array}{l}\text { história ensino } \\
\text { poder hoje }\end{array}$ & $\begin{array}{l}\text { consciência } \\
\text { rüsen funk } \\
\text { escravizar } \\
\text { narrativo }\end{array}$ & \\
\hline 500 & $\begin{array}{l}\text { consciência } \\
\text { metodologia } \\
\text { investigação } \\
\text { pensamento } \\
\text { metodológico }\end{array}$ & antigo publicar & $\begin{array}{l}\text { história ensino } \\
\text { poder hoje }\end{array}$ & $\begin{array}{l}\text { consciência } \\
\text { rüsen funk } \\
\text { narrativo turma } \\
\text { unilab discente }\end{array}$ & \\
\hline
\end{tabular}

Fonte: Elaboração dos autores. 
As palavras mais usadas no corpus completo da Revista Brasileira de História, apresentado na Tabela 5 (na próxima página), são obviamente as três palavras que compõem seu título, que poderiam ser consideradas palavras vazias. Podemos afirmar que entre as palavras mais importantes estão "poder" (que flutua entre a $2^{\underline{a}}$ e a $6^{\mathrm{a}}$ posição), "político" (2 $2^{\mathrm{a}}$ à $15^{\mathrm{a}}$ posição), "social" (4a à $16^{\mathrm{a}}$ posição), "estado" (5a à 18 posição) e "novo" (9a à 18ª ). Também é interessante observar por que as palavras "indígena”, “documento", “escravo", "água”, "antigo”, "região”, “militar”, "classe" e "liberdade" aparecem em branco entre as primeiras palavras, ou seja, aparecem de forma significativa apenas em um dos corpora anuais.

Por uma questão de espaço, não analisaremos todas as palavras que aparecem na Tabela 6 , mas apenas destacaremos dentre os fenômenos que podem ser observados nela: a ascensão das palavras "nacional" e "América”, a queda das palavras "trabalho", "processo" e "governo" e a ascensão repentina das palavras "antigo" e "antiguidade" (por se repetirem em várias linhas da tabela).

Para observar mais de perto essas palavras selecionadas na Tabela 4, utilizamos dois códigos em Google Apps Script (de extensão gs) disponíveis na pasta "code" do projeto hospedado na Open Science Framework (https://osf. io/bepqd/files/). As planilhas criadas por este último código para cada uma das palavras listadas no parágrafo anterior (nacional, América, trabalho, processo, governo, antigo e antiguidade) encontram-se disponíveis em formato xlsx na pasta "dataset/RBH/08_specific_words" do projeto hospedado na Open Science Framework (https://osf.io/bepqd/files/).

Dentre as palavras em ascensão, "nacional” passou de 149 menções em 2012 para 196 menções em 2020 e "América” passou de 69 menções em 2012 para 124 menções em 2020, o que pode ser conferido nos arquivos xlsx citados no parágrafo anterior. As hipóteses para esses fenômenos são o crescimento da preocupação do campo com os temas relacionados a estas palavras. Dentre as palavras em queda, "trabalho" passou de 271 menções em 2012 para 88 menções em 2020, "processo" passou de 195 menções em 2012 para 89 menções em 2020 e "governo" passou de 151 menções em 2012 para 89 menções em 2020. A queda no uso da palavra "trabalho" significaria uma redução das produções sobre história do trabalho paralela à precarização do trabalho e às reformas trabalhistas em voga? A queda no uso da palavra "governo" significaria uma redução da produção de história política ou uma ressignificação dessa história para além da história dos governos? Dentre as palavras que apresen- 
Tabela 5 - As 19 palavras mais usadas no corpus completo da $\mathrm{RBH}$ e nos corpora anuais, seguidas do número de vezes em que cada uma delas aparece em cada corpus.

\begin{tabular}{|c|c|c|c|c|c|c|c|c|c|}
\hline $\begin{array}{l}\text { Corpus } \\
\text { completo }\end{array}$ & 2012 & 2013 & 2014 & 2015 & 2016 & 2017 & 2018 & 2019 & 2020 \\
\hline $\begin{array}{l}\text { história, } \\
12997\end{array}$ & $\begin{array}{l}\text { história, } \\
1217\end{array}$ & $\begin{array}{l}\text { história, } \\
1718\end{array}$ & $\begin{array}{l}\text { história, } \\
1248\end{array}$ & $\begin{array}{l}\text { história, } \\
1270\end{array}$ & $\begin{array}{l}\text { história, } \\
1564\end{array}$ & $\begin{array}{l}\text { história, } \\
1584\end{array}$ & $\begin{array}{l}\text { história, } \\
1293\end{array}$ & $\begin{array}{l}\text { história, } \\
1384\end{array}$ & $\begin{array}{l}\text { história, } \\
1719\end{array}$ \\
\hline $\begin{array}{l}\text { brasileiro, } \\
9009\end{array}$ & $\begin{array}{l}\text { poder, } \\
949\end{array}$ & $\begin{array}{l}\text { político, } \\
966\end{array}$ & $\begin{array}{l}\text { brasileiro, } \\
978\end{array}$ & $\begin{array}{l}\text { brasileiro, } \\
959\end{array}$ & $\begin{array}{l}\text { brasileiro, } \\
1231\end{array}$ & $\begin{array}{l}\text { revista, } \\
943\end{array}$ & $\begin{array}{l}\text { arquivo, } \\
1051\end{array}$ & $\begin{array}{l}\text { rio, } \\
1335\end{array}$ & $\begin{array}{l}\text { brasileiro, } \\
1069\end{array}$ \\
\hline $\begin{array}{l}\text { revista, } \\
6632\end{array}$ & $\begin{array}{l}\text { brasileiro, } \\
890\end{array}$ & $\begin{array}{l}\text { poder, } \\
911\end{array}$ & $\begin{array}{l}\text { poder, } \\
724\end{array}$ & $\begin{array}{l}\text { revista, } \\
783\end{array}$ & $\begin{array}{l}\text { brasil, } \\
966\end{array}$ & $\begin{array}{l}\text { brasileiro, } \\
938\end{array}$ & $\begin{array}{l}\text { brasileiro, } \\
1018\end{array}$ & $\begin{array}{l}\text { brasileiro, } \\
1075\end{array}$ & $\begin{array}{l}\text { revista, } \\
955\end{array}$ \\
\hline $\begin{array}{l}\text { poder, } \\
6560\end{array}$ & $\begin{array}{l}\text { político, } \\
729\end{array}$ & $\begin{array}{l}\text { brasileiro, } \\
851\end{array}$ & $\begin{array}{l}\text { brasil, } \\
688\end{array}$ & $\begin{array}{l}\text { terra, } \\
749\end{array}$ & $\begin{array}{l}\text { revista, } \\
794\end{array}$ & $\begin{array}{l}\text { poder, } \\
690\end{array}$ & $\begin{array}{l}\text { revista, } \\
787\end{array}$ & $\begin{array}{l}\text { revista, } \\
798\end{array}$ & $\begin{array}{l}\text { poder, } \\
654\end{array}$ \\
\hline $\begin{array}{l}\text { rio, } \\
5590 \\
\end{array}$ & $\begin{array}{l}\text { brasil, } \\
641\end{array}$ & $\begin{array}{l}\text { social, } \\
695\end{array}$ & $\begin{array}{l}\text { político, } \\
656 \\
\end{array}$ & $\begin{array}{l}\text { poder, } \\
606\end{array}$ & $\begin{array}{l}\text { poder, } \\
718\end{array}$ & $\begin{array}{l}\text { indígena, } \\
657\end{array}$ & $\begin{array}{l}\text { brasil, } \\
661\end{array}$ & $\begin{array}{l}\text { poder, } \\
718\end{array}$ & $\begin{array}{l}\text { brasil, } \\
484\end{array}$ \\
\hline $\begin{array}{l}\text { brasil, } \\
5542\end{array}$ & $\begin{array}{l}\text { rio, } \\
617\end{array}$ & $\begin{array}{l}\text { estado, } \\
579\end{array}$ & $\begin{array}{l}\text { rio, } \\
611\end{array}$ & $\begin{array}{l}\text { negro, } \\
591\end{array}$ & $\begin{array}{l}\text { sérgio, } \\
661\end{array}$ & $\begin{array}{l}\text { político, } \\
641\end{array}$ & $\begin{array}{l}\text { poder, } \\
590\end{array}$ & $\begin{array}{l}\text { brasil, } \\
590\end{array}$ & $\begin{array}{l}\text { paulo, } \\
484\end{array}$ \\
\hline $\begin{array}{l}\text { político, } \\
5526\end{array}$ & $\begin{array}{l}\text { trabalho, } \\
608\end{array}$ & $\begin{array}{l}\text { brasil, } \\
541\end{array}$ & $\begin{array}{l}\text { paulo, } \\
541\end{array}$ & $\begin{array}{l}\text { rio, } \\
588\end{array}$ & $\begin{array}{l}\text { político, } \\
645\end{array}$ & $\begin{array}{l}\text { rio, } \\
577\end{array}$ & $\begin{array}{l}\text { paulo, } \\
568\end{array}$ & $\begin{array}{l}\text { político, } \\
562\end{array}$ & $\begin{array}{l}\text { rio, } \\
454\end{array}$ \\
\hline $\begin{array}{l}\text { paulo, } \\
4297\end{array}$ & $\begin{array}{l}\text { revista, } \\
599\end{array}$ & $\begin{array}{l}\text { revista, } \\
531\end{array}$ & $\begin{array}{l}\text { trabalho, } \\
505\end{array}$ & $\begin{array}{l}\text { brasil, } \\
538\end{array}$ & $\begin{array}{l}\text { estado, } \\
500\end{array}$ & $\begin{array}{l}\text { índio, } \\
556\end{array}$ & $\begin{array}{l}\text { documento, } \\
532\end{array}$ & $\begin{array}{l}\text { paulo, } \\
474\end{array}$ & $\begin{array}{l}\text { político, } \\
451\end{array}$ \\
\hline $\begin{array}{l}\text { social, } \\
4210\end{array}$ & $\begin{array}{l}\text { primeiro, } \\
546\end{array}$ & $\begin{array}{l}\text { novo, } \\
525\end{array}$ & $\begin{array}{l}\text { novo, } \\
475\end{array}$ & $\begin{array}{l}\text { político, } \\
526\end{array}$ & $\begin{array}{l}\text { rio, } \\
499\end{array}$ & $\begin{array}{l}\text { social, } \\
527\end{array}$ & $\begin{array}{l}\text { rio, } \\
521\end{array}$ & $\begin{array}{l}\text { social, } \\
451\end{array}$ & $\begin{array}{l}\text { século, } \\
395\end{array}$ \\
\hline $\begin{array}{l}\text { estado, } \\
3745\end{array}$ & $\begin{array}{l}\text { janeiro, } \\
483\end{array}$ & $\begin{array}{l}\text { primeiro, } \\
418\end{array}$ & $\begin{array}{l}\text { janeiro, } \\
451\end{array}$ & $\begin{array}{l}\text { social, } \\
516\end{array}$ & $\begin{array}{l}\text { paulo, } \\
489\end{array}$ & $\begin{array}{l}\text { trabalho, } \\
444\end{array}$ & $\begin{array}{l}\text { escravo, } \\
489\end{array}$ & $\begin{array}{l}\text { português, } \\
444\end{array}$ & $\begin{array}{l}\text { janeiro, } \\
370\end{array}$ \\
\hline $\begin{array}{l}\text { novo, } \\
3682\end{array}$ & $\begin{array}{l}\text { estado, } \\
480\end{array}$ & $\begin{array}{l}\text { século, } \\
408\end{array}$ & $\begin{array}{l}\text { revista, } \\
442\end{array}$ & $\begin{array}{l}\text { paulo, } \\
473\end{array}$ & $\begin{array}{l}\text { novo, } \\
472\end{array}$ & $\begin{array}{l}\text { paulo, } \\
435\end{array}$ & $\begin{array}{l}\text { público, } \\
458\end{array}$ & $\begin{array}{l}\text { água, } \\
443\end{array}$ & $\begin{array}{l}\text { social, } \\
348\end{array}$ \\
\hline $\begin{array}{l}\text { janeiro, } \\
3577\end{array}$ & $\begin{array}{l}\text { novo, } \\
467\end{array}$ & $\begin{array}{l}\text { nacional, } \\
408\end{array}$ & $\begin{array}{l}\text { estado, } \\
433\end{array}$ & $\begin{array}{l}\text { estado, } \\
428\end{array}$ & $\begin{array}{l}\text { social, } \\
449\end{array}$ & $\begin{array}{l}\text { brasil, } \\
433\end{array}$ & $\begin{array}{l}\text { janeiro, } \\
437\end{array}$ & $\begin{array}{l}\text { século, } \\
438\end{array}$ & $\begin{array}{l}\text { antigo, } \\
322\end{array}$ \\
\hline $\begin{array}{l}\text { trabalho, } \\
3385\end{array}$ & $\begin{array}{l}\text { paulo, } \\
454\end{array}$ & $\begin{array}{l}\text { governo, } \\
399\end{array}$ & $\begin{array}{l}\text { social, } \\
411\end{array}$ & $\begin{array}{l}\text { janeiro, } \\
427\end{array}$ & $\begin{array}{l}\text { primeiro, } \\
402\end{array}$ & $\begin{array}{l}\text { guerra, } \\
393\end{array}$ & $\begin{array}{l}\text { estado, } \\
388\end{array}$ & $\begin{array}{l}\text { região, } \\
402\end{array}$ & $\begin{array}{l}\text { nacional, } \\
321\end{array}$ \\
\hline $\begin{array}{l}\text { século, } \\
3315\end{array}$ & $\begin{array}{l}\text { trabalhador, } \\
453\end{array}$ & $\begin{array}{l}\text { trabalho, } \\
390\end{array}$ & $\begin{array}{l}\text { trabalhador, } \\
388\end{array}$ & $\begin{array}{l}\text { novo, } \\
419\end{array}$ & $\begin{array}{l}\text { janeiro, } \\
385\end{array}$ & $\begin{array}{l}\text { século, } \\
376\end{array}$ & $\begin{array}{l}\text { social, } \\
365\end{array}$ & $\begin{array}{l}\text { público, } \\
397\end{array}$ & $\begin{array}{l}\text { primeiro, } \\
312\end{array}$ \\
\hline $\begin{array}{l}\text { primeiro, } \\
3277\end{array}$ & $\begin{array}{l}\text { tempo, } \\
450\end{array}$ & $\begin{array}{l}\text { rio, } \\
388\end{array}$ & $\begin{array}{l}\text { nacional, } \\
369\end{array}$ & $\begin{array}{l}\text { trabalho, } \\
392\end{array}$ & $\begin{array}{l}\text { livro, } \\
380\end{array}$ & $\begin{array}{l}\text { primeiro, } \\
361\end{array}$ & $\begin{array}{l}\text { político, } \\
350\end{array}$ & $\begin{array}{l}\text { novo, } \\
345\end{array}$ & $\begin{array}{l}\text { estado, } \\
299\end{array}$ \\
\hline $\begin{array}{l}\text { nacional, } \\
2768\end{array}$ & $\begin{array}{l}\text { social, } \\
448\end{array}$ & $\begin{array}{l}\text { paulo, } \\
379\end{array}$ & $\begin{array}{l}\text { primeiro, } \\
330\end{array}$ & $\begin{array}{l}\text { século, } \\
375\end{array}$ & $\begin{array}{l}\text { trabalho, } \\
375\end{array}$ & $\begin{array}{l}\text { novo, } \\
356\end{array}$ & $\begin{array}{l}\text { século, } \\
341\end{array}$ & $\begin{array}{l}\text { estado, } \\
343\end{array}$ & $\begin{array}{l}\text { novo, } \\
293\end{array}$ \\
\hline $\begin{array}{l}\text { público, } \\
2673\end{array}$ & $\begin{array}{l}\text { século, } \\
439\end{array}$ & $\begin{array}{l}\text { janeiro, } \\
346\end{array}$ & $\begin{array}{l}\text { tempo, } \\
321\end{array}$ & $\begin{array}{l}\text { trabalhador, } \\
364\end{array}$ & $\begin{array}{l}\text { histórico, } \\
369\end{array}$ & $\begin{array}{l}\text { janeiro, } \\
340\end{array}$ & $\begin{array}{l}\text { nacional, } \\
340\end{array}$ & $\begin{array}{l}\text { janeiro, } \\
338\end{array}$ & $\begin{array}{l}\text { obra, } \\
284\end{array}$ \\
\hline $\begin{array}{l}\text { histórico, } \\
2521\end{array}$ & $\begin{array}{l}\text { segundo, } \\
386\end{array}$ & $\begin{array}{l}\text { dia, } \\
337\end{array}$ & $\begin{array}{l}\text { política, } \\
319\end{array}$ & $\begin{array}{l}\text { índio, } \\
334\end{array}$ & $\begin{array}{l}\text { nacional, } \\
361\end{array}$ & $\begin{array}{l}\text { estado, } \\
295\end{array}$ & $\begin{array}{l}\text { novo, } \\
330\end{array}$ & $\begin{array}{l}\text { primeiro, } \\
325\end{array}$ & $\begin{array}{l}\text { público, } \\
277\end{array}$ \\
\hline $\begin{array}{l}\text { tempo, } \\
2509\end{array}$ & $\begin{array}{l}\text { militar, } \\
376\end{array}$ & $\begin{array}{l}\text { classe, } \\
323\end{array}$ & $\begin{array}{l}\text { governo, } \\
316\end{array}$ & $\begin{array}{l}\text { nacional, } \\
327\end{array}$ & $\begin{array}{l}\text { buarque, } \\
360\end{array}$ & $\begin{array}{l}\text { histórico, } \\
289\end{array}$ & $\begin{array}{l}\text { liberdade, } \\
318\end{array}$ & $\begin{array}{l}\text { segundo, } \\
307\end{array}$ & $\begin{array}{l}\text { josé, } \\
267\end{array}$ \\
\hline
\end{tabular}

Fonte: Elaboração dos autores.

taram ascensão repentina, "antigo" passou de 18 menções em 2019 (ano em que teve o menor número de menções) para 74 menções em 2020 e "antiguidade" passou de nenhuma menção em 2019 (ano em que teve o menor número de menções) para 102 menções em 2020. A ascensão do uso das palavras "antigo" e "antiguidade" tem relação apenas com temáticas privilegiadas em 
números específicos da RBH ou com uma ascensão da importância da História Antiga no campo?

\section{Tabela 6 - Fenomenologia semântico-temporal das palavras mais usadas na RBH.}

\begin{tabular}{|c|c|c|c|c|c|}
\hline & Ascensão & Queda & Estabilidade & $\begin{array}{l}\text { Ascensão } \\
\text { repentina }\end{array}$ & $\begin{array}{l}\text { Aparecimento } \\
\text { repentino }\end{array}$ \\
\hline Palavras & $\begin{array}{l}\text { 1. Como explicar } \\
\text { a ascensão da(s) } \\
\text { palavra(s) x, y...? } \\
\text { - presente em } \\
\text { todos os períodos } \\
\text { (min >0); } \\
\text { - termina mais } \\
\text { alto que } \\
\text { começou (swing } \\
\text { e delta } \\
\text { positivos); } \\
\text { - começa entre as } \\
50 \% \text { últimas } \\
\text { palavras ( } 1^{\circ} \\
\text { valor de data } \\
<\text { metade do no } \\
\text { de itens); } \\
\text { - termina entre as } \\
\text { palavras do } \\
\text { primeiro quarto } \\
\text { do ranking } \\
\text { (primeiras } 25 \% \text { ). }\end{array}$ & $\begin{array}{l}\text { 2. Como explicar } \\
\text { a queda da(s) } \\
\text { palavra(s) x, y...? } \\
\text { - presente em } \\
\text { todos os } \\
\text { períodos (min > } \\
0 \text { ); } \\
\text { - termina mais } \\
\text { baixo que } \\
\text { começou (swing } \\
\text { e delta } \\
\text { negativos); } \\
\text { - começa entre as } \\
50 \% \text { primeiras } \\
\text { palavras ( } 1^{\circ} \\
\text { valor de data > } \\
\text { metade do nº de } \\
\text { itens); } \\
\text { - termina entre as } \\
\text { palavras do } \\
\text { último quarto } \\
\text { do ranking } \\
\text { (últimas } 25 \% \text { ). }\end{array}$ & $\begin{array}{l}\text { 3. Por que a(s) } \\
\text { palavra(s) } \mathbf{x}, \mathbf{y} . . . \text { é } \\
\text { (são) estável(is) } \\
\text { na primeira } \\
\text { metade das } \\
\text { palavras mais } \\
\text { usadas? } \\
\text { - presente em } \\
\text { todos os } \\
\text { períodos } \\
\text { (min }>0 \text { ); } \\
\text { - stdev <2.5; } \\
\text { - termina entre as } \\
50 \% \text { primeiras } \\
\text { palavras (último } \\
\text { valor de data > } \\
\text { metade do no de } \\
\text { itens). }\end{array}$ & $\begin{array}{l}\text { 4. Como explicar } \\
\text { a ascensão } \\
\text { repentina da(s) } \\
\text { palavra(s) x, y...? } \\
\text { - presente em um } \\
\text { dos dois últimos } \\
\text { períodos } \\
\text { (sem 0 no data } \\
\text { nos dois últimos } \\
\text { períodos); } \\
\text { - termina entre as } \\
25 \% \text { primeiras } \\
\text { palavras; } \\
\text { - swing e delta > } \\
75 \% \text {. }\end{array}$ & $\begin{array}{l}\text { 5. Como explicar } \\
\text { o surgimento } \\
\text { repentino da(s) } \\
\text { palavra }(\mathrm{s}) \mathrm{x}, \mathrm{y} . . . \text { ? } \\
\text { - presente apenas } \\
\text { nos períodos da } \\
2^{\mathrm{a}} \text { metade (sem } \\
0 \text { no data na } 2^{\mathrm{a}} \\
\text { metade e com } 0 \\
\text { na } 1^{\mathrm{a}} \text { metade); } \\
\text { - min }=0 .\end{array}$ \\
\hline 20 & & & $\begin{array}{l}\text { história poder } \\
\text { brasileiro }\end{array}$ & & \\
\hline 30 & & & $\begin{array}{l}\text { história poder } \\
\text { brasileiro }\end{array}$ & & \\
\hline 40 & & & $\begin{array}{l}\text { história poder } \\
\text { brasileiro }\end{array}$ & & \\
\hline 50 & nacional & trabalho & $\begin{array}{l}\text { história poder } \\
\text { brasileiro }\end{array}$ & antigo & \\
\hline 60 & nacional & trabalho processo & $\begin{array}{l}\text { história poder } \\
\text { brasileiro }\end{array}$ & antigo & \\
\hline 70 & público nacional & processo & $\begin{array}{l}\text { história poder } \\
\text { brasileiro }\end{array}$ & antigo & universidade \\
\hline 80 & nacional & governo & $\begin{array}{l}\text { história poder } \\
\text { brasileiro }\end{array}$ & antigo & \\
\hline 90 & & governo & $\begin{array}{l}\text { história poder } \\
\text { brasileiro }\end{array}$ & antigo & \\
\hline
\end{tabular}




\begin{tabular}{|c|c|c|c|c|c|}
\hline 100 & & governo & $\begin{array}{l}\text { história poder } \\
\text { brasileiro }\end{array}$ & antigo cultural & \\
\hline 200 & $\begin{array}{l}\text { cultura contexto } \\
\text { universidade }\end{array}$ & lei análise & $\begin{array}{l}\text { história poder } \\
\text { brasileiro }\end{array}$ & $\begin{array}{l}\text { antigo historiar } \\
\text { university history } \\
\text { sus saudade } \\
\text { esclavo correio } \\
\text { grego jazz }\end{array}$ & área \\
\hline 250 & $\begin{array}{l}\text { discurso } \\
\text { universidade } \\
\text { américa }\end{array}$ & dia jornal sempre & $\begin{array}{l}\text { história poder } \\
\text { brasileiro }\end{array}$ & $\begin{array}{l}\text { médico historiar } \\
\text { university history } \\
\text { sus saudade } \\
\text { esclavo correio } \\
\text { grego jazz } \\
\text { antiguidade }\end{array}$ & área \\
\hline 300 & $\begin{array}{c}\text { antigo américa } \\
\text { debate }\end{array}$ & $\begin{array}{l}\text { terra escravo } \\
\text { região dia direito } \\
\text { sempre objetivo } \\
\text { razão }\end{array}$ & $\begin{array}{l}\text { história poder } \\
\text { brasileiro }\end{array}$ & $\begin{array}{l}\text { médico historiar } \\
\text { university history } \\
\text { sus saudade } \\
\text { esclavo correio } \\
\text { grego jazz } \\
\text { antiguidade } \\
\text { clássico doença } \\
\text { romano abreu }\end{array}$ & \\
\hline 400 & $\begin{array}{l}\text { historiografia } \\
\text { debate }\end{array}$ & força & $\begin{array}{l}\text { história poder } \\
\text { brasileiro }\end{array}$ & $\begin{array}{l}\text { negro médico } \\
\text { historiar } \\
\text { university history } \\
\text { sus saudade } \\
\text { esclavo correio } \\
\text { grego jazz } \\
\text { antiguidade } \\
\text { clássico doença } \\
\text { romano abreu } \\
\text { wikipédia saúde } \\
\text { horácio poeta } \\
\text { chile saint }\end{array}$ & \\
\hline 500 & history sistema & $\begin{array}{l}\text { arquivo família } \\
\text { civil }\end{array}$ & $\begin{array}{l}\text { história poder } \\
\text { brasileiro }\end{array}$ & $\begin{array}{l}\text { negro médico } \\
\text { historiar } \\
\text { university sus } \\
\text { saudade esclavo } \\
\text { correio grego jazz } \\
\text { antiguidade } \\
\text { clássico doença } \\
\text { abreu wikipédia } \\
\text { saúde global } \\
\text { horácio poeta } \\
\text { chile saint oxford } \\
\text { miguel pele } \\
\text { bezerro airar not } \\
\text { buenos }\end{array}$ & \\
\hline
\end{tabular}

Fonte: Elaboração dos autores. 
Qual seria o significado da ascensão repentina da palavra "antigo" no corpus da RBH: antigo está sendo usado como adjetivo ou trata-se de um crescimento nos estudos sobre a antiguidade? Enquanto a RHHJ viu ascender rapidamente as palavras "debate" e "gênero", a RBH viu ascender "área" e "universidade". Em termos de debate público contemporâneo, o que isso significa? Como as questões mais relevantes no debate público atual chegam à produção dessas revistas? Estaria a RBH fazendo uma defesa da própria história enquanto a RHHJ se insere de forma mais contundente em outros temas? O objetivo de estudos semântico-temporais com este não é responder a essas questões, mas levantá-las para que possam ser respondidas pelo campo ou auxiliá-lo a gerar outras questões derivadas delas. Um exemplo de como um estudo neste formato pode ser útil a outros historiadores está no uso feito por Carmem Zeli de Vargas Gil no artigo “A sala de aula nas publicações da Revista História Hoje (2015-2017)" publicado entre as páginas 84 e 108 desta mesma edição.

\section{REFERÊNCIAS}

ANDERSEN, H.; BARKER, P.; CHEN, X. The Cognitive Structure of Scientific Revolutions. Cambridge: Cambridge University Press, 2006.

CARDOSO, O. The social flow of historical narratives and its many names. Esboços: histórias em contextos globais, v. 26 n. 43, p. 573-596, set.-dez. 2019.

CHRISTENSEN, Garret; FREESE, Jeremy; MIGUEL, Edward. Transparent and Reproducible Social Science Research: How to Do Open Science. Oakland: University of California Press, 2019.

DEELMAN, E. et alii. The future of scientific workflows. The International Journal of High Performance Computing Applications, v. 32 n. 1, p. 159-175, 2017.

BEZJAK, S. et alii. Manual de Formação em Ciência Aberta. 2018. Disponível em: https://book.fosteropenscience.eu/pt/book.pdf. https://doi.org/10.5281/zenodo.1212496. Acesso em: 30 mai. 2021.

IOANNIDIS, J. Why Most Published Research Findings Are False. PLoS Med v. 2, n. 8: e124, 2005. https://doi.org/10.1371/journal.pmed.0020124.

KANWAL, J.; SMITH, K.; CULBERTSON, J.; KIRBY, S. Zipf's Law of Abbreviation and the Principle of Least Effort: Language users optimise a miniature lexicon for efficient communication. Cognition, Amsterdam, v. 165, p. 45-52, 2017.

KOSCHTIAL, Claudia; KÖHLER, Thomas; FELDEN, Carsten (orgs.). e-Science: 
Open, Social and Virtual Technology for Research Collaboration. Cham: Springer, 2021.

KUHN, T. S. The Structure of Scientific Revolutions. Chicago: The University of Chicago Press, 1996.

MARCUM, J. A. From Paradigm to Disciplinary Matrix and Exemplar. In: KINDI, V;; ARABATZIS, T. Kuhn's The structure of scientific revolutions revisited. New York: Routledge, 2012.

MORENO-SÁNCHEZ, I.; FONT-CLOS, F.; CORRAL, Á. Large-Scale Analysis of Zipf's Law in English Texts, PLoS ONE, San Francisco/Cambridge, v. 11, n. 1, 2016. https://doi.org/10.1371/journal.pone.0147073.

OECD (Organisation for Economic Co-operation and Development). Making Open Science a Reality. (OECD Science, Technology and Industry Policy Papers, 25). Paris: OECD Publishing, 2015.

PONTIKA, Nancy; KNOTH, Petr; CANCELLIERI, Matteo; PEARCE, Samuel. Fostering Open Science to Research using a Taxonomy and an eLearning Portal. In: iKnow: 15th International Conference on Knowledge Technologies and Data Driven Business, p. 21-22, out. 2015, Graz, Austria. https://doi. org/10.1145/2809563.2809571.

SILVA, E. A.; SILVA, J. M. Ofício, Engenho e Arte: Inspiração e Técnica na Análise de Dados Qualitativos. Revista Latino-americana de Geografia e Gênero, Ponta Grossa, v. 7, n. 1, p. 132-154, 2016.

WILLIAMS, J. R.; BAGROW, J. P.; REAGAN, A. J.; ALAJAJIAN, S. E.; DANFORTH, C. M.; DODDS, P. S. Zipf's law is a consequence of coherent language production. arXiv, Ithaca. https://arxiv.org/abs/1601.07969v2, 2016.

ZIPF, G. K. Human Behavior and the Principle of Least Effort. Cambridge: Addison-Wesley, 1949.

Artigo submetido em 30 de maio de 2021. 